\title{
Isolated tricuspid valve surgery; long-term outcomes based on Tehran Heart Center data bank report
}

Seyed Hosssein Ahmadi Tafti ${ }^{1}$, Farshid Alaeddini ${ }^{1}$, Mahmood Shirzad ${ }^{1}$, Jamshid Bagheri ${ }^{1}$, Abbas Salehi Omran ${ }^{1}$, Mehrdad Mahalleh², Shiva Shoja ${ }^{3}$ and Negar Omidi ${ }^{1^{*}}$ (D)

\begin{abstract}
Background: Given that isolated tricuspid valve (TV) repair or replacement is performed relatively rarely, we sought to evaluate the rate of long-term mortality and readmission following this surgery.

Methods: The current study was conducted in Tehran Heart Center on patients who underwent isolated TV repair or replacement between 2010 and 2018. Totally, 197 patients (repair $=150$ vs replacement $=47$ ) were included in our study and were then followed right after surgery for a median of 8 years to assess the incidence of postoperative events, readmission, and all-cause mortality.

Results: The final analysis was conducted on 197 patients at a mean age of $44.4 \pm 13.8$ years. Most of the patients were female (56.9\%). Ejection fraction, TAPSE, and right ventricular function improved in both groups after TV surgery. Length of stay in the intensive care unit per hour and hospitalization per day were higher in the replacement group and compared to the repair group (158.34 vs. 55.11 and 18.21 vs. 9.34, respectively). In-hospital mortality occurred in 20 patients, of whom 15 had TV replacement. Readmission occurred in five (2.5\%) patients,all were in the repair group.

Conclusions: The result of this single-center study showed that TV replacement is associated with a higher rate of postoperative events and all-cause mortality compared to TV repair. Whereas, repair group had a higher rate of readmission. Therefore, the overwhelming tendency is toward repair; nonetheless, no hesitation is permissible if a replacement is adjudged to confer a better outcome for the patient.
\end{abstract}

Keywords: Tricuspid valve, Valve repair/replacement, In-hospital mortality

\section{Introduction}

Tricuspid valve (TV) disease is far less common than is mitral or aortic valve involvement, and it is often ignored because its regurgitation or stenosis can be well tolerated [1-3]. TV regurgitation that leads to surgery can be either organic or secondary. The etiologies of organic TV disease include rheumatic fever, tumors such as myxomas and carcinoids, genetic diseases such as

\footnotetext{
* Correspondence: negar.omidi@gmail.com

${ }^{1}$ Tehran Heart Center, Tehran University of Medical Sciences, Tehran, Iran Full list of author information is available at the end of the article
}

Marfan's disorder, and congenital diseases such as Ebstein's anomaly. Secondary causes are mostly due to left-heart pathologies such as left-side heart failure, progressive biventricular dysfunction, and pulmonary hypertension. The severity of TV dysfunction tends to rise steadily, and it is mostly diagnosed when patients develop significant symptoms [4]. The majority of patients are controlled with pharmacotherapy until it fails, necessitating their referral to surgeons for decision-making on the repair or replacement of the valve based on the symptoms and severity of the disease. Isolated TV repair

C C The Author(s). 2021 Open Access This article is licensed under a Creative Commons Attribution 4.0 International License, which permits use, sharing, adaptation, distribution and reproduction in any medium or format, as long as you give appropriate credit to the original author(s) and the source, provide a link to the Creative Commons licence, and indicate if changes were made. The images or other third party material in this article are included in the article's Creative Commons licence, unless indicated otherwise in a credit line to the material. If material is not included in the article's Creative Commons licence and your intended use is not permitted by statutory regulation or exceeds the permitted use, you will need to obtain permission directly from the copyright holder. To view a copy of this licence, visit http://creativecommons.org/licenses/by/4.0/ The Creative Commons Public Domain Dedication waiver (http://creativecommons.org/publicdomain/zero/1.0/) applies to the data made available in this article, unless otherwise stated in a credit line to the data. 
is feasible, whereas TV replacement is not frequently performed due to the high rate of short- and long-term morbidity and mortality based on the characteristics of patients and other concomitant disorders [5, 6].

Previous studies have evaluated the short- and longterm outcomes of TV repair or TV replacement in other countries [7-9] but there are limited studies about outcomes of isolated TV surgery in middle income countries. We, therefore, aimed to assess the incidence of the long-term morbidity and mortality of isolated TV repairing by ring annuloplasty or tricuspid replacement with or without atrial septal defect (ASD) closure in Tehran Heart Center.

\section{Methods}

\section{Study population}

This retrospective cohort study was performed using the Tehran Heart Center Valve Surgery Data Bank. All the patients who had TV repair or replacement between 2010 and 2018 whose information was recorded in our database were enroled. The exclusion criteria were concomitant mitral valve replacement and aortic valve replacement and uncompleted recorded data. All the stages, from data collection to data analysis, were performed without revealing the identity of the patients. The study protocol was approved by the institutional ethics committee and research board.

\section{Follow-up protocol}

In keeping with the protocol of the Tehran Heart Center Surgery Data Bank, general practitioners and research nurses interviewed and examined the patients to complete their data on symptoms, major risk factors of cardiovascular disease, and baseline characteristics. The patients were observed and interviewed during hospitalization and for a 30-day period after surgery to record any early in-hospital mortality and readmission. In addition, long-termfollow-up was done to evaluate the echocardiographic indices and incidence of postoperative events among the patients whether they were readmitted to our center or elsewhere.

\section{Study endpoints}

The major endpoints of our study were comprised of 1) determining the incidence of all-causein-hospital mortality, 2) determining the rate of postoperative events and readmission over a 30-day period, and 3) determining the incidence of mortality within 8 years.

\section{Statistical analysis}

Categorical variables are presented as percentage (number) and were evaluated using chi-squared test or Fisher's exact test. Continuous variables are presented as mean \pm standard deviation. Analyses of continuous variables were done using student's t-test. SPSS 20.0 statistical software (IBM, Chicago, IL, USA) was used for data analysis and $P \leq 0.05$ was the criterion of significance.

\section{Results \\ Population}

The study population was comprised of 197 patients at a mean age of $44.4 \pm 13.8$ years and a mean body mass index of $24.9 \pm 4.4 \mathrm{~kg} / \mathrm{cm}^{2}$ who underwent TV repair or replacement either solely or with concomitant ASD surgical closure. Women accounted for $56.9 \%(n=112)$ of the patients. The median follow-up period was 57.6 months.

TV repair was performed in 150 (76.1\%) patients, bioprosthetic valve replacement in 41 (87.23\%), and mechanical valve replacement in $6(12.77 \%)$.

All the patients were investigated for postoperative complications, readmission, and 30-dayin-hospital mortality and were included in the final analysis. The baseline characteristics of the study population are summarized in Table 1.

Concerning the etiology of TV disease, rheumatic valve etiology was more common in the replacement group than in the repair group $(76.6 \%$ vs. $20 \%)$, whereas ASD was more prevalent in the repair group (79.5\% vs. $17 \%)$.

\section{Endpoints}

Based on the results of the study, there was an improvement in the left ventricular ejection fraction in both groups postoperatively (Table 2). Furthermore, tricuspid annular plane systolic excursion (TAPSE), which is a marker of right ventricular (RV) function, was improved following surgery (Table 2). Postoperative events occurred in $3.33 \%$ of the repair group and $21.27 \%$ of the replacement group. The median time interval to the first event was 2.5 (2.12) and 6.3 (3.5) months after surgery in the repair and replacement groups, respectively. Table 2 shows the postoperative echocardiographic outcomes of the study population after surgery. As is shown, the incidence of endocarditis was higher in the repair group than in the replacement group, but the frequency of valve malfunction and redo surgery was higher in the replacement group. Intensive care unit (ICU) hours and the ventilation time were higher in the replacement group and, consequently, the length of hospital stay was also higher in this group (Table 2). Higher total ICU hours were not statistically associated with high preoperative pulmonary arterial pressure (PAP) in the replacement group and the repair group (correlation: $0.275, P=0.082$ vs $0.060, P=0.470$, respectively), but the association has clinical significance in the replacement group. The rate of all-cause mortality in the 
Table 1 Baseline characteristics and echocardiography features of the study population

\begin{tabular}{|c|c|c|c|}
\hline \multirow[t]{2}{*}{ Characteristic } & \multicolumn{2}{|l|}{ Implant Type } & \multirow[t]{2}{*}{$P$-value } \\
\hline & Repair $(n=150)$ & Replacement $(n=47)$ & \\
\hline \multicolumn{4}{|l|}{ Demographics } \\
\hline Age, mean (SD) & $43.0(13.6)$ & $48.8(13.5)$ & 0.011 \\
\hline Gender (female), n (\%) & $81(54.0)$ & $31(66.0)$ & 0.149 \\
\hline Body mass index, mean (SD) & $24.9(4.4)$ & $24.9(4.4)$ & 0.931 \\
\hline \multicolumn{4}{|c|}{ Past Medical History and Risk Factors } \\
\hline Diabetes, n (\%) & $6(4.0)$ & $6(12.8)$ & 0.039 \\
\hline Hyperlipidemia, n (\%) & $20(13.4)$ & $11(23.4)$ & 0.102 \\
\hline Rheumatic valve, n (\%) & $30(20.0)$ & $36(76.6)$ & $<0.0001$ \\
\hline Atrial septal defect, n (\%) & $120(79.5)$ & $8(17.0)$ & \\
\hline \multicolumn{4}{|l|}{ Pre-operation } \\
\hline NYHA functional class, mean (SD) & $1.75(0.73)$ & $1.98(0.74)$ & \\
\hline Ejection fraction, mean (SD) & $49.74(5.76)$ & $47.37(7.83)$ & 0.002 \\
\hline TAPSE, mean (SD) & $21.27(6.93)$ & $17.50(7.30)$ & 0.005 \\
\hline RVD, mean (SD) & $44.09(8.21)$ & $39.47(8.87)$ & 0.003 \\
\hline PAP, mean (SD) & $39.76(12.57)$ & $40.21(12.73)$ & 0.452 \\
\hline
\end{tabular}

NYHA New York Heart Association, TAPSE Tricuspid annular plane systolic excursion, RVD Right ventricular dysfunction, PAP Pulmonary arterial pressure Continuous variables are presented as the mean (SD) or the median (25th and 75th percentiles)

Categorical variables are described as frequencies (percentages); $\mathrm{n}(\%)$

Table 2 Echocardiographic features and outcomes of the study population

\begin{tabular}{|c|c|c|c|}
\hline \multirow[t]{2}{*}{ Characteristic } & \multicolumn{2}{|l|}{ Implant Type } & \multirow[t]{2}{*}{$P$ Value } \\
\hline & Repair $(n=150)$ & Replacement $(n=47)$ & \\
\hline \multicolumn{4}{|l|}{ Post-operation } \\
\hline Dyspnea & $24(16.0)$ & $5(10.6)$ & 0.365 \\
\hline Orthopnea & $0(0.0)$ & $1(2.1)$ & 0.239 \\
\hline Palpitation & $4(2.7)$ & $2(4.3)$ & 0.630 \\
\hline Acute chest pain & $2(1.3)$ & $1(2.1)$ & 0.561 \\
\hline NYHA functional class, mean (SD) & $1.05(0.25)$ & $1.12(0.42)$ & 0.373 \\
\hline Ejection fraction, mean (SD) & $51.12(5.02)$ & $47.72(5.50)$ & 0.005 \\
\hline TAPSE, mean (SD) & $16.80(3.52)$ & $16.20(3.77)$ & 0.422 \\
\hline RVD, mean (SD) & $34.80(6.31)$ & $32.20(5.33)$ & 0.064 \\
\hline PAP, mean (SD) & $32.00(9.29)$ & $30.66(8.06)$ & 0.514 \\
\hline$I C U, h$ & $55.11(54.08)$ & $158.34(286.67)$ & 0.020 \\
\hline Ventilation time & $14.91(30.25)$ & $89.56(256.44)$ & 0.058 \\
\hline Length of stay, $d$ & $9.34(4.48)$ & $18.21(16.39)$ & 0.001 \\
\hline \multicolumn{4}{|l|}{ Events } \\
\hline Readmission & $5(3.3)$ & $0(0.0)$ & 0.341 \\
\hline Malfunction/valve thrombosis & $2(1.3)$ & $3(6.4)$ & 0.089 \\
\hline Redo surgery & $0(0.0)$ & $7(14.8)$ & 0.000 \\
\hline Hemorrhagic stroke & $1(0.6)$ & $0(0.0)$ & 1.000 \\
\hline Endocarditis & $2(1.3)$ & $0(0.0)$ & 1.000 \\
\hline Mortality & $5(3.3)$ & 15 (32.6) & 0.000 \\
\hline
\end{tabular}

NYHA New York Heart Association, TAPSE Tricuspid annular plane systolic excursion, RVD Right ventricular dysfunction, PAP Pulmonary arterial pressure, ICU Intensive care unit 
replacement group was higher than that in the repair group, (32.6\% vs $3.3 \%$, respectively). Only five (3.3\%) patients from repair group readmitted to the hospital (Table 2).

\section{Discussion}

In the present study, we evaluated long-term mortality and morbidity between 2 groups of TV repair and TV replacement over a median of 8 years. We found that mortality was higher (32.6\%) in the replacement group than in the repair group (25.9\%); nevertheless, this finding should be interpreted in light of the fact that our study sample was small. Consistent with our results, previous studies have also concluded that TV replacement is associated with considerably high mortality compared with TV repair [10, 11]. Guenther et al. evaluated 416 patients over a median of 5.9 years and found that 30 day mortality after TV repair was $13.9 \%$ (43/310) opposed to $33 \%(35 / 106)$ after TV replacement $(P=$ $0.0001)$ [10]. In line with it, multiple studies have reported that the in-hospital mortality after TV replacement ranges between 14.5 and $48 \%$ [12]. It is crucial for surgeons to select their patients cautiously to reduce the rate of mortality after TV replacement. Topilsky et al. also believed that candidating the right patient for TV replacement might lower the rate of mortality [13].

There are other independent predictors of mortality after isolated TV surgeries such as the New York Heart Association (NYHA) functional class $[13,14]$ and RV function parameters $[13,15]$. These variables should be considered in the decision for the medical or surgical treatment of TV disease. It is apparent that both of them play central roles in both preoperative clinical status and postoperative outcomes [4,16-18]. As is shown in our results, postoperative RV dysfunction and the NYHA functional class improved in both groups by comparison with the preoperative measurements, and we detected no correlation between either TAPSE or the NYHA functional class and mortality. Bevan et al. [19] and Buzzatti et al. [20] posited that RV dysfunction played an important role in preoperative characteristics such as ascites and also postoperative outcomes. Topilsky et al. reported that a preoperative NYHA functional class of 4 was associated with a higher chance of mortality [13]. In a propensity score study, Calafiore et al. showed that functional benefits were present with moderate-tosevere functional tricuspid regurgitation subjected to mitral surgery if the TV was concomitantly diseased [21].

There are different causes of readmission after TV surgery irrespective of the type of Surgery (repair vs. replacement) including congestive heart failure (CHF), arrhythmia, respiratory and surgical complications, cerebrovascular arrest, infections and acute kidney injury [22]. In our study, only repair group experienced readmission due to $\mathrm{CHF}$, renal failure, transient ischemic attack and valve dysfunction. The patients in replacement group had higher rate of mortality.

PAP is associated with worse outcomes in patients undergoing isolated tricuspid surgery [14]. Likewise, we observed a drop in postoperative PAP in both groups. Preoperative PAP had a significant correlation with the length of stay in the ICU, and it was strongly higher in the RV replacement group. Buzzatti et al. observed a relationship between the presence of a higher PAP leading to poor outcomes and mortality in their patients undergoing TV replacement. Similarly, Mangoni et al. concluded that one of the factors associated with poor outcomes was a high PAP [6]. We believe that the high preoperative PAP in our replacement group might have resulted in the higher rate of mortality in this group.

We have previously demonstrated that redo surgery is a major determinant of early and long-term mortality [3, 5 , 23]. In this study, we also observed that none of the patients in the TV repair group had redo surgery, whereas $14 \%$ of the TV replacement group patients were scheduled for redo surgery, which can cause a lower rate of survival in a longer follow-up period. Great precaution may be needed when performing redo surgery in patients with isolated TV disease due to the high recurrence of tricuspid regurgitation after redo surgery [23]. Our results also revealed that only $3.5 \%$ of the entire study population ( $n=7,14.8 \%$ in the replacement group) needed redo surgery, which is lower than the rates in previous studies [24-27].

Rheumatic etiology is one of the most important predictors of a poor outcome. This is understandable because rheumatic disease is a destructive and ongoing process causing extensive and sometimes irreparable damage not only to the TV but also to the myocardium [28]. We found that the incidence of rheumatic valve disease was higher in the TV replacement group than in the TV repair group (76.6\% vs $20.0 \%)$. Moreover, our results revealed a higher mortality rate in the replacement group. Previous studies have also reported that rheumatic heart disease is correlated with mortality in patients after TV surgery $[6,28]$. It can be referred from our results that rheumatic valve disease might have caused the high mortality in our TV replacement group compared with our TV repair group.

We had 1 patient with hemorrhagic stroke in the TV repair group who had a history of atrial fibrillation and was on vitamin $\mathrm{K}$ antagonist regimen. Postoperative neurological impairment after cardiac surgery is a serious complication. In a recent study, Raffa et al. evaluated the incidence of different types of stroke after a variety of cardiac surgeries and found that the incidence of hemorrhagic stroke was relatively low compared with ischemic stroke and it 
occurred in patients undergoing concomitant cardiac surgeries (TV surgery concomitant with coronary artery bypass graft or aortic valve surgery) [29].

Based on the past medical history of our patients, most of the ASD cases were in the TV repair group $(79.5 \%$ vs $17.0 \%)$ rather than in the TV replacement group. ASD closure surgery is one of the concomitant procedures in TV surgery [30].

In our study, we found that ICU hours and the length of hospital stay were significantly higher in the replacement group, even though this group comprised fewer patients than did the repair group. Alqahtani et al. evaluated the outcomes of surgical treatment in 45,477 patients, $15 \%$ of whom only had isolated tricuspid surgery. They found that TV surgery was associated with a long duration of hospitalization, which is reported to be higher in other types of valve surgeries [31]. In another study, TV replacement and repair propensity-matched cohorts had similar ICU lengths of stay, but the replacement group had a significantly longer hospital length of stay [32].

It is believed that diabetes, the level of creatinine, and the white blood cell count play important roles in mortality insofar as they can increase the chance of postoperative infection and mortality afterward. Among the patients who died in the present study, 3 patients had leukocytosis due to urinary tract infection, which caused septicemia and led to death. This finding is concordant with the results reported by Fowler et al., who reported a higher rate of complications such as longer lengths of hospital stay and higher rates of mortality in patients with major infections after cardiac surgery [33].

In the current study, we had 2 patients with endocarditis as the etiology of repair surgery; both of them expired. (The power of the study made it impossible to evaluate the statistical difference.) Nonetheless, Singh et al. reported that the organic pathology of the valve could significantly increase the occurrence of mortality in TV replacement as opposed to TV repair irrespective of the type of implant. Pfannmüller et al. concluded that mortality could be higher if surgery was performed under urgent conditions due to endocarditis or other cardiac diseases [3]. The discrepancy between the results of the present study and those previously reported might be due to our small sample size. We, thus, recommend further evaluations on larger sample volumes.

\section{Study limitations}

We did not calculate the predictive score of mortality (eg, the EuroSCORE), nor did we assess the reoccurrence rate of postoperative regurgitation. In addition, the study population was relatively small and we were unable to perform a long-termfollow-up on our patients. Moreover, there were differences in the some of the baseline characteristics of the study population. Another salient weakness of our study is our failure to record information concerning the presence of ascites and anasarca, which have major associations with mortality. It must be mentioned, due to low percentage of mortality, evaluating the predictors of the mortality in either groups, was not the aim of present study.

\section{Conclusions}

This retrospective study of isolated TV surgery, conducted in a single center over nearly a decade, showed that replacement, by comparison with repair, was associated with a high rate of postoperative events, mortality, and lower readmission, which confirms why it is performed rarely. Further studies with larger sample size are required.

\section{Abbreviations \\ ASD: Atrial septal defect; CHF: Congestive heart failure; ICU: Intensive care unit; NYHA: New York Heart Association; PAP: Pulmonary arterial pressure; RV: Right ventricle; TAPSE: Tricuspid annular plane systolic excursion; TV: Tricuspid valve}

\section{Acknowledgements}

No acknowledgments to declare.

\section{Authors' contributions}

$\mathrm{NO}$ and SHAT contributed to the study conception and design. Material preparation, data collection and analysis were performed by FA, NO and MM. The first draft of the manuscript was written by NO and all authors commented on previous versions of the manuscript. All authors read and approved the final manuscript.

\section{Funding}

The authors received no financial support for the research, authorship, and/ or publication of this article.

\section{Availability of data and materials}

The datasets used and/or analysed during the current study are available from the corresponding author on reasonable request.

\section{Ethics approval and consent to participate}

The study protocol was approved by the institutional ethics committee and research board.

\section{Consent for publication}

Not applicable.

\section{Competing interests}

The authors declare that there is no conflict of interest.

\section{Author details}

${ }^{1}$ Tehran Heart Center, Tehran University of Medical Sciences, Tehran, Iran. ${ }^{2}$ Cardiovascular Research Center, Tehran University of Medical Sciences, Tehran, Iran. ${ }^{3} \mathrm{Al}$-Zahra Hospital, Isfahan University of Medical Sciences, Isfahan, Iran.

Received: 28 September 2020 Accepted: 16 February 2021

Published online: 23 February 2021

\section{References}

1. Chen J, Abudupataer M, Hu K, Maimaiti A, Lu S, Wei L, et al. Risk factors associated with perioperative morbidity and mortality following isolated tricuspid valve replacement. J Surg Res. 2018;221:224-31.

2. Nath J, Foster E, Heidenreich PA. Impact of tricuspid regurgitation on longterm survival. J Am Coll Cardiol. 2004;43(3):405-9. 
3. Pfannmüller B, Moz M, Misfeld M, Borger MA, Funkat A-K, Garbade J, et al. Isolated tricuspid valve surgery in patients with previous cardiac surgery. J Thorac Cardiovasc Surg. 2013;146(4):841-7.

4. Singh SK, Tang GH, Maganti MD, Armstrong S, Williams WG, David TE, et al. Midterm outcomes of tricuspid valve repair versus replacement for organic tricuspid disease. Ann Thorac Surg. 2006;82(5):1735-41.

5. Garatti A, Nano G, Bruschi G, Canziani A, Colombo T, Frigiola A, et al. Twenty-five year outcomes of tricuspid valve replacement comparing mechanical and biologic prostheses. Ann Thorac Surg. 2012;93(4):1146-53.

6. Mangoni AA, DiSalvo TG, Vlahakes GJ, Polanczyk CA, Fifer MA. Outcome following isolated tricuspid valve replacement. Eur J Cardiothorac Surg. 2001;19(1):68-73.

7. Ejiofor Jl, Neely RC, Yammine M, McGurk S, Kaneko T, Leacche M, et al. Surgical outcomes of isolated tricuspid valve procedures: repair versus replacement. Ann Cardiothorac Surg. 2017;6(3):214.

8. Zack CJ, Fender EA, Chandrashekar P, Reddy YN, Bennett CE, Stulak JM, et al. National trends and outcomes in isolated tricuspid valve surgery. J Am Coll Cardiol. 2017;70(24):2953-60.

9. Wong WK, Chen SW, Chou AH, Lee HA, Cheng YT, Tsai FC, et al. Late outcomes of valve repair versus replacement in isolated and concomitant tricuspid valve surgery: a Nationwide cohort study. J Am Heart Assoc. 2020; 9(8):e015637.

10. Guenther T, Noebauer C, Mazzitelli D, Busch R, Tassani-Prell P, Lange R. Tricuspid valve surgery: a thirty-year assessment of early and late outcome. Eur J Cardiothorac Surg. 2008;34(2):402-9.

11. Alkhouli M, Berzingi C, Kowatli A, Alqahtani F, Badhwar V. Comparative early outcomes of tricuspid Valve repair versus replacement for secondary tricuspid regurgitation. Open Heart. 2018;5(2):e000878.

12. Northrup WF, DuBois KA, Kshettry VR, Teskey J, Nicoloff D. Trends in aortic valve surgery in a large multi-surgeon, multi-hospital practice, 1979-1999. J Heart Valve Dis. 2002;11(6):768-79.

13. Topilsky Y, Khanna AD, Oh JK, Nishimura RA, Enriquez-Sarano M, Jeon YB, et al. Preoperative factors associated with adverse outcome after tricuspid valve replacement. Circulation. 2011;123(18):1929-39.

14. De Meester P, Van De Bruaene A, Voigt J-U, Herijgers P, Budts W. Outcome and determinants of prognosis in patients undergoing isolated tricuspid valve surgery: retrospective single center analysis. Int J Cardiol. 2014;175(2): 333-9.

15. Kim Y-J, Kwon D-A, Kim H-K, Park J-S, Kim K-H, Sohn D-W, et al. Determinants of surgical outcome in patients with isolated tricuspid regurgitation. Circulation. 2009;120:1672.

16. Oh TH, Wang TK, Sidhu K, Haydock DA. Isolated tricuspid valve surgery at a single Centre: the 47-year Auckland experience, 1965-2011. Interact Cardiovasc Thorac Surg. 2014;18(1):27-32.

17. McCarthy PM, Bhudia SK, Rajeswaran J, Hoercher K, Lytle BW, Cosgrove DM, et al. Tricuspid valve repair: durability and risk factors for failure. J Thorac Cardiovasc Surg. 2004;127(3):674-85.

18. Ghanta RK, Chen R, Narayanasamy N, McGurk S, Lipsitz S, Chen FY, et al. Suture bicuspidization of the tricuspid valve versus ring annuloplasty for repair of functional tricuspid regurgitation: midterm results of 237 consecutive patients. J Thorac Cardiovasc Surg. 2007:133(1):117-26.

19. Bevan PJ, Haydock DA, Kang N. Long-term survival after isolated tricuspid valve replacement. Heart Lung Circulation. 2014;23(8):697-702.

20. Buzzatti N, laci G, Taramasso M, Nisi T, Lapenna E, De Bonis M, et al. Longterm outcomes of tricuspid valve replacement after previous left-side heart surgery. Eur J Cardiothorac Surg. 2014;46(4):713-9.

21. Calafiore AM, Gallina S, lacò AL, Contini M, Bivona A, Gagliardi M, et al. Mitral valve surgery for functional mitral regurgitation: should moderate-ormore tricuspid regurgitation be treated? A propensity score analysis. Ann Thorac Surg. 2009;87(3):698-703.

22. Dhoble A, Peerbhai S, Zhao Y, Vejpongsa P, Garcia-Sayan E, Smalling RW, et al. Rates, predictors, and outcomes of early readmissions after tricuspid valve surgery. J Card Surg. 2020;35:1848.

23. Hwang HY, Kim K-H, Kim K-B, Ahn H. Reoperations after tricuspid valve repair: re-repair versus replacement. J Thorac Dis. 2016;8(1):133.

24. Carrier $M$, Hebert $Y$, Pellerin $M$, Bouchard D, Perrault LP, Cartier R, et al. Tricuspid valve replacement: an analysis of 25 years of experience at a single center. Ann Thorac Surg. 2003;75(1):47-50.

25. Chang HW, Jeong DS, Cho YH, Sung K, Kim WS, Lee YT, et al. Tricuspid valve replacement vs. repair in severe tricuspid regurgitation. Circ J. 2017; 81(3):330-8.
26. Marquis-Gravel $G$, Bouchard $D$, Perrault LP, Pagé $P$, Jeanmart $H$, Demers $P$, et al. Retrospective cohort analysis of 926 tricuspid valve surgeries: clinical and hemodynamic outcomes with propensity score analysis. Am Heart J. 2012:163(5):851-8. e1.

27. Ratnatunga CP, Edwards M-B, Dore CJ, Taylor KM. Tricuspid valve replacement: UK heart valve registry mid-term results comparing mechanical and biological prostheses. Ann Thorac Surg. 1998;66(6):1940-7.

28. Iscan ZH, Vural KM, Bahar I, Mavioglu L, Saritas A. What to expect after tricuspid valve replacement? Long-term results. Eur J Cardiothorac Surg. 2007;32(2):296-300.

29. Raffa GM, Agnello F, Occhipinti G, Miraglia R, Lo Re V, Marrone G, et al. Neurological complications after cardiac surgery: a retrospective case-control study of risk factors and outcome. J Cardiothorac Surg. 2019;14(1):23.

30. Ricci D, Boffini M, Barbero C, El Qarra S, Marchetto G, Rinaldi M. Minimally invasive tricuspid valve surgery in patients at high risk. J Thorac Cardiovasc Surg. 2014;147(3):996-1001

31. Alqahtani F, Berzingi CO, Aljohani S, Hijazi M, Al-Hallak A, Alkhouli M. Contemporary trends in the use and outcomes of surgical treatment of tricuspid regurgitation. J Am Heart Assoc. 2017;6(12):e007597.

32. Moraca RJ, Moon MR, Lawton JS, Guthrie TJ, Aubuchon KA, Moazami N, et al. Outcomes of tricuspid valve repair and replacement: a propensity analysis. Ann Thorac Surg. 2009:87(1):83-9.

33. Fowler VG Jr, O'Brien SM, Muhlbaier LH, Corey GR, Ferguson TB, Peterson ED. Clinical predictors of major infections after cardiac surgery. Circulation. 2005;112(9_supplement):I-358-1-65.

\section{Publisher's Note}

Springer Nature remains neutral with regard to jurisdictional claims in published maps and institutional affiliations.
Ready to submit your research? Choose BMC and benefit from:

- fast, convenient online submission

- thorough peer review by experienced researchers in your field

- rapid publication on acceptance

- support for research data, including large and complex data types

- gold Open Access which fosters wider collaboration and increased citations

- maximum visibility for your research: over $100 \mathrm{M}$ website views per year

At BMC, research is always in progress.

Learn more biomedcentral.com/submissions 